\title{
O Sonho de Johannes Kepler: uma tradução do primeiro texto de hard sci-fi
}

The Dream by Johannes Kepler: a translation of the first hard sci-fi text

\author{
Jair Lúcio Prados Ribeiro*1
}

${ }^{1}$ Universidade de Brasília, Instituto de Química, Programa de Pós-Graduação em Educação em Ciências, Brasília, DF, Brazil

Recebido em 29 de Maio, 2017. Revisado em 20 de Junho, 2017. Aceito em 28 de Junho, 2017.

\begin{abstract}
O artigo apresenta uma tradução do texto póstumo de Johannes Kepler, intitulado Somnium, o qual foi publicado em 1634. Apesar de ter sido originalmente publicado como um tratado sobre a astronomia lunar, o formato do texto permite classificá-lo também como um precursor da ficção científica moderna. São sugeridas também algumas atividades pedagógicas, adequadas para a educação básica, que poderiam ser desenvolvidas a partir do manuscrito.
\end{abstract}

Palavras-chave: história da astronomia, história da ciência, Johannes Kepler, ficção científica.

The article presents a translation of Johannes Kepler's posthumous text entitled Somnium, which was published in 1634. Although it was originally published as a treatise on lunar astronomy, the format of the text also allows it to be classified as a forerunner of modern science fiction. Also, some pedagogical activities are suggested, suitable for basic education, which could be developed from the manuscript.

Keywords: history of astronomy, history of science, Johannes Kepler, science fiction.

\section{Introdução}

No terceiro episódio da clássica série de divulgação científica Cosmos - a personal voyage [1], intitulado $A$ harmonia dos mundos, o apresentador e astrônomo Carl Sagan reconta a turbulenta vida de Johannes Kepler (1571-1630). Na passagem que encerra o episódio, Sagan correlaciona a chegada do homem à Lua e a sonhada expansão da humanidade pelo espaço com um onírico escrito póstumo de Kepler sobre a astronomia lunar, intitulada Somnium [2] - literalmente, O Sonho (Figura 1).

Apesar de não ser exatamente obscura, a obra em questão não figura entre os escritos mais conhecidos desse filósofo natural. De acordo com Anderson [3], Kepler começou a desenvolver o manuscrito de Somnium ainda como estudante na cidade alemã de Tübingen em 1593. Nessa primeira versão, o filósofo natural em formação buscava desenvolver uma argumentação a favor do sistema heliocêntrico copernicano. Para isso, Kepler descreveu os movimentos aparentes da Terra a partir de uma Lua "estacionária", uma consideração que levava a um importante corolário: se a Lua se adequava como base para a construção de teorias sobre tais movimentos (ainda que ela não estivesse estacionária na realidade), o mesmo poderia ser verificado para a Terra.

A oposição à polêmica tese de Kepler foi veemente no âmbito da sua universidade, fazendo com que o filósofo natural só pudesse vir a retrabalhar o texto dezesseis anos

*Endereço de correspondência: jairlucio@gmail.com mais tarde. Kepler tomou então a decisão de reescrever o manuscrito a partir do contexto de um sonho - daí o adequado título Somnium. Da influente análise de Marjorie Nicolson [4] sobre a forma final desse manuscrito, depreende-se que a autora o entende como um trabalho que não pode ser negligenciado na história das teorias astronômicas sobre a Lua, descrevendo-o como o primeiro texto no qual uma viagem espacial é abordada a partir da ciência moderna e classificando-o como uma fonte primária para as diversas "viagens cósmicas" que vieram a ser escritas durante o século XVII e XVIII - em especial, o livro L'Histoire comique des États et Empires de la Lune [5] 11 publicado em 1655, de autoria do francês Cyrano de Bergerac (1619-1655).

Não nos causa consternação, portanto, que Gingerich [6] e Swinford [7] se refiram ao curto tratado de Kepler ${ }^{2}$ como uma obra de ficção cientifica. Embora tal termo seja de difícil definição - dada a ampla variedade de obras, em diferentes mídias, que são açabarcadas pelo mesmo - entendemos que obras de ficção científica lidam, via de regra, com as consequências da ciência sobre a sociedade ou sobre indivíduos particulares; ou ainda, como Johnson [8] afirma, "a ficção científica nos fornece uma linguagem para falarmos sobre o futuro" (p.91). O texto Somnium, a nosso ver, pode ser interpretado a partir de tais definições, na medida em que Kepler o construiu como um relato de uma viagem ficcional para a

\footnotetext{
1 Título em português: História cômica dos Estados e Impérios da Lua.

${ }^{2} \mathrm{Na}$ versão original em latim [2], o texto tinha vinte e oito páginas.
} 


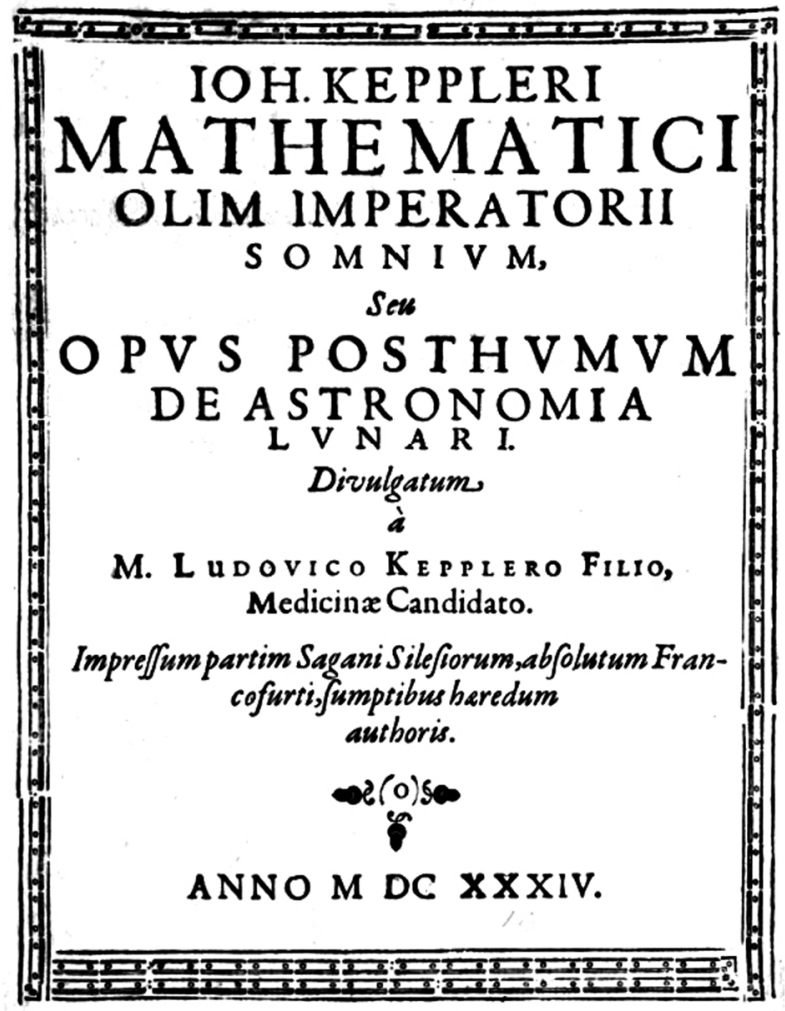

Figura 1: Capa do manuscrito original [2].

Lua mais de três séculos antes de tal jornada efetivamente ocorrer. Frisa-se ainda que essa viagem espacial entre os dois corpos do Sistema Solar também está presente na clássica obra De la Terre à la Lune [9] 33, publicada em 1865 pelo romancista francês Jules Verne (1828-1905). O livro em questão é considerado como uma obra de ficção científica desde a sua publicação inicial, estabelecendo um paralelo importante para que se possa falar de Somnium como uma obra sci-fi ${ }^{4}$

Grosso modo, há duas vertentes principais na ficção científica, definidas na língua inglesa pelos termos soft ou hard. Como essa própria nomenclatura permite antever, a ficção científica soft trata a ciência com menor rigor, chegando por vezes a desconsiderar ou subverter por completo as teorias científicas atuais. Exemplos desse estilo de narrativa incluem a obra supracitada de Cyrano de Bergerac [5] e a "ópera espacial" cinematográfica Star Wars 5 , lançada em 1977. Já as obras classificadas como ficção científica hard são aquelas nas quais o autor demonstra uma maior preocupação com o ideário científico, buscando compatibilizá-lo com a história a ser contada e, por vezes, conferindo-lhe grande destaque no enredo. Dois exemplos proeminentes de hard $s c i$ - $f i$ são os livros

\footnotetext{
3 Título em português: Da Terra à Lua.

$4 S c i$-fi é uma abreviatura tradicionalmente usada em inglês para se referir à expressão science fiction.

5 Título em português: Guerra nas Estrelas.
}

2001 a space odyssey [10] ${ }^{6}$ de Arthur Clarke (1917-2008) e Tau zero [11] 7 de Poul Anderson (1926-2001).

Nesse âmbito, o divulgador científico Marcelo Gleiser [12] destaca que o texto de Kepler apresenta um caráter mágico e sobrenatural no tocante ao deslocamento para a Lua, fato que o afastaria da ficção científica hard; todavia, Gleiser também ressalta que a análise astronômica dos fenômenos celestiais observados do ponto de vista dos seres lunares se apoiava nas teorias científicas de então, algumas desenvolvidas pelo próprio Kepler. Ainda segundo Gleiser, Kepler chegou até mesmo a antecipar alguns aspectos da teoria darwiniana, ao imaginar a adaptação dos seres lunares aos diferentes ambientes em que eles viveriam. Vem daí a afirmação de Bozzetto [13], para quem "Somnium pode ser visto como um importante ancestral geral da ficção científica hard da atualidade" (p.370).

Durante a vida de Kepler, Somnium circulou apenas na forma de manuscrito, a partir de cópias "piratas" de uma versão de 1609 [3]. O manuscrito não ganhou tanta notoriedade quanto seu autor a princípio desejava, mas repercutiu negativamente no julgamento eclesiástico ao qual a mãe de Kepler foi submetida em 1615, sob a acusação da prática de bruxaria. Algumas passagens do manuscrito foram citadas então como evidências em tal julgamento, pois Kepler atribuiu em Somnium a viagem da Terra à Lua aos poderes mágicos da mãe. Assim, após a árdua via crucis burocrática enfrentada pelo filósofo até a absolvição de sua genitora, Kepler decidiu reelaborar novamente o texto, incluindo um amplo conjunto de notas explicativas (223 ao todo) ao manuscrito original - conforme o próprio autor relata, havia praticamente uma nota por sentença [3] - escritas ao longo da sua última década de vida. Essas notas conferem um caráter mais formal ao texto, e permitem insights sobre as teorias de Kepler - por exemplo, em uma das notas, ele considera que a atração entre dois corpos celestes era inversamente proporcional à distância e não ao quadrado da distância, como Isaac Newton (1643-1727) viria a descrever posteriormente.

De acordo com Christianson [14], o artifício narrativo de colocar o texto no enquadramento de um sonho tinha duas justificativas principais: haveria uma menor objeção dentre aqueles que defendiam o sistema ptolomaico, ao apresentar a ideia como um delírio incontrolável, advindo da letargia, permitindo afastar a defesa do sistema copernicano de uma argumentação herética; e consentiria a Kepler a introdução de um agente mítico (chamado Daemon no texto), o qual seria capaz de transportar humanos para a superfície lunar.

Pode-se afirmar que Kepler tinha a intenção de supervisionar a publicação do manuscrito: afinal, em 1630, quando adveio sua súbita morte, seis páginas do mesmo já haviam sido impressas [14]. Após seu falecimento, as condições econômicas precárias da sua viúva induziram seu filho Ludovico (ou Ludwig, em alemão) a publicar

\footnotetext{
6 Título em português: 2001 uma odisseia no espaço.

7 Título em português: Tau zero.
} 
o volume póstumo em 1634. Nessa versão em latim, a qual se encontra disponível na íntegra na internet [2] em uma digitalização do livro original, estão incluídos o texto Somnium e o extenso conjunto de notas do autor, além de apêndices sobre a geografia lunar e uma obra do historiador e filósofo grego Plutarco De Facies in orbe lunae 8 , a qual foi traduzida da língua grega para a latina pelo próprio Kepler.

De acordo com Rosen [15], Somnium foi republicado em latim apenas no século XIX. Duas versões parciais para o alemão foram apresentadas em 1871 e 1898, enquanto uma tradução completa para o inglês só veio a ser publicada em 1965 por Kirkwood e Lear [16], sendo esta brevemente seguida, dois anos depois, pela tradução de Rosen [15]. Entretanto, durante a nossa pesquisa, tomamos conhecimento de uma tradução anterior para o inglês elaborada por Falardeau [17], a qual não é mencionada por Rosen. Usamos essa versão como base para a nossa tradução, na medida em que a mesma se encontra disponível on-line e se encontra em domínio público. Tal tradução foi desenvolvida de forma independente pelo reverendo Normand Falardeau em 19629 , o qual a elaborou como parte da sua dissertação de mestrado. O autor, entretanto, não a publicou no formato de um livro tradicional, razão que contribuiu para a sua relativa obscuridade em relação às traduções supracitadas. Vale destacar que, no resumo de seu texto, Falardeau justificou o resgate do seminal texto de Kepler devido ao papel de protagonista que a Lua havia adquirido durante a década de 1960, a qual foi dominada pela corrida espacial e culminou com a chegada de uma missão norte-americana ao satélite em 1969.

Desconhecemos a existência de uma tradução de Somnium para o português, daí nossa intenção em apresentála no artigo presente. Entretanto, ainda que tal tradução já exista, consideramos que novos esforços de tradução são sempre louváveis, na medida em que permitem a rediscussão do texto original e mesmo a comparação entre as traduções existentes.

Cabe frisar de antemão que, para os fins desse artigo, apresentamos a tradução apenas do manuscrito original em si. As notas explicativas, embora relevantes, exigiriam um trabalho adicional de proporções monumentais, e o tamanho do texto resultante provavelmente não seria adequado, a nosso ver, às dimensões dos artigos dessa publicação, exigindo um formato alternativo - quiçá um livro. Ademais, na busca de uma compatibilidade com o escopo dessa revista, consideramos que a pequena extensão do texto o qualifica para uso em aulas de física na educação básica, conforme argumentamos nas considerações finais desse trabalho. Recomendamos ao leitor que deseje consultar tais notas a leitura da obra de Rosen [15], que as apresenta na íntegra; alertamos, entretanto, que o próprio tradutor inclui suas próprias notas e comentários acerca das notas de Kepler, fato que torna a leitura bastante densa e, por vezes, fastidiosa.

\footnotetext{
8 Título em português: As faces da Lua.

9 O reverendo Normand Raymond Falardeau faleceu em 2004.
}

Ao contrário, o curto texto de Somnium é, a nosso ver, bastante fluido e de leitura rápida, características que tentamos reproduzir na tradução que aqui apresentamos.

Apesar de termos tomado como base para a elaboração dessa tradução a versão para o inglês de Falardeau [17], na medida em que nosso domínio do latim científico é precário, buscamos também consultar a versão original [2] de 1634 para conferir como Kepler escrevia alguns termos. Admitimos também que, para um melhor entendimento de passagens e contextos específicos, consultamos por vezes a tradução elaborada por Rosen [15]. Também foram de grande auxílio para a elaboração dessa tradução os resumos críticos presentes nos textos de Nicolson [4] e Christianson [14], os quais se revelaram bastante explicativos, facilitando nossa interpretação de passagens do texto original. Para melhor compreensão de algumas frases, decidimos ainda pela inserção de algumas palavras ou expressões, as quais estão identificadas entre colchetes.

Três narradores estão presentes na história de Somnium: o primeiro narrador (no nosso entendimento e também de Nicolson [4], o próprio Kepler) inicia a história, descrevendo que caiu no sono enquanto lia sobre a história da Boêmia. Durante o sonho, ele se encontra lendo um livro que ele teria comprado em Frankfurt, um relato autobiográfico de um segundo narrador, chamado Duracotus - o qual Nicolson [4] defende ser também o próprio Kepler, dadas as similaridades biográficas expostas no texto. O islandês Duracotus reconta então suas viagens e seus estudos sobre a astronomia, realizados sob a supervisão de Tycho Brahe (um personagem histórico real, crucial também na biografia de Kepler), até que finalmente ele se reúne com a mãe Fiolxhilda, a qual exibe características de uma feiticeira ou, ao menos, mística (o paralelo com a mãe de Kepler, acusada de bruxaria, também é notável nessa passagem). A mãe de Duracotus evoca então uma entidade, nomeada Daemon, que assume o papel de terceiro narrador do texto, descrevendo a viagem até a Lua e também as características da geografia lunar e da vida daqueles que lá habitam.

Para facilitar o entendimento do leitor, vale destacar de antemão que, ao longo do texto, Kepler se refere à Lua como uma "ilha nas alturas", chamada Levânia. Já os seres que habitam a superfície da Lua se referem à Terra como Volva. Dois hemisférios lunares, com características geográficas e celestiais bastante distintas, são referenciados: o hemisfério Subvolva, cuja face está sempre voltada para a Terra, e o hemisfério Privolva ${ }^{10}$ cuja face está voltada para o lado oposto à Terra. Tal oposição no posicionamento em relação à Terra leva a fenômenos bastante diferentes nesses dois hemisférios, em especial no tocante à duração do dia e da noite, à temperatura ambiente e à possibilidade de observação de eclipses.

Cabe frisar ainda, antes de apresentarmos a tradução em si, que a defesa pelo uso da ficção científica em aulas de física já possui tradição na literatura acadêmica em

10 Kepler utiliza em Somnium também adjetivos pátrios referentes a Subvolva e Privolva. Nessa tradução, decidimos pelo uso de subvolvanianos e privolvanianos para tais adjetivos. 
ensino de ciências: ainda nos anos 1980, o livro de Dubeck et al. [18] já defendia a discussão de filmes sci-fi em sala de aula, argumentando que tanto estudantes de graduação quanto de ensino médio tendem a preferir a fantasia à ciência, fazendo com que tal estratégia ajude a superar a apatia em relação às ciências naturais. Já Dark [19] argumenta que atividades em aulas de ciência inspiradas pela ficção científica encorajam o pensamento criativo e podem ser usadas para desenvolver habilidades de escrita, enquanto Piassi e Pietrocola [20] propõem ir além do método didático da "busca por erros" 11 em obras de ficção científica (tanto literárias quanto cinematográficas), na medida em que a esse modelo de ficção constitui uma modalidade específica de discurso sobre a ciência, nas quais as questões científicas são discutidas sob um contexto de influência sociocultural. Assim, acreditamos que disponibilizar tal tradução pode contribuir para novas propostas de ensino de física, algumas das quais estão citadas nas considerações finais desse artigo.

\section{Tradução}

\subsection{O Sonho}

Em 1608, quando as discórdias se desencadearam entre os dois irmãos, o príncipe Rodolfo II e o arquiduque Matias, a população examinou suas ações, comparandoas com exemplos tirados da história da Boêmia. Naquela época, fui impulsionado pela mesma curiosidade e passei a me dedicar ao estudo das lendas boêmias. Quando me deparei com a lenda do virago líbio, tão celebrado na arte da magia, algo aconteceu. Certa noite, depois de ter contemplado atentamente a Lua e as estrelas, eu me sentei pacificamente na minha poltrona e caí num sono bastante profundo. Em meu sonho, eu parecia pegar um livro da estante a fim de lê-lo. O teor do livro era o seguinte:

Meu nome é Duracotus e minha pátria a Islândia, chamada Thule pelos antigos. Minha mãe, Fiolxhilda, morreu recentemente, deixando-me livre para escrever algo que eu já desejava ardentemente produzir. Enquanto viveu, ela diligentemente cuidou para que eu não escrevesse [esse texto], pois ela dizia que havia muitos maliciosos usurpadores das artes que, por não entenderem nada, devido à ignorância de suas mentes, as deturpavam e faziam leis prejudiciais para a raça humana. Sob essas leis, muitos homens certamente haviam sido condenados e engolidos nos abismos de Hekla. O nome do meu pai ela nunca me disse. Ela afirmava que ele era um pescador, o qual tinha morrido na idade de cento e cinquenta, quando eu tinha três anos de idade. Eles estiveram casados por setenta anos, mais ou menos.

Na minha infância, minha mãe me guiava pela mão ou, me levantando nos braços, frequentemente me trazia para

11 Devemos frisar, entretanto, que consideramos válido tal método didático de comparar a ficção com a realidade, destacando seus erros e acertos, e inclusive propomos nas considerações finais desse artigo uma aplicação dessa prática didática a partir do texto aqui traduzido. os cumes mais baixos do Monte Hekla, especialmente por volta da época da festa de São João, quando o Sol ficava visível por vinte e quatro horas e não deixava espaço para a noite. Ela recolhia muitas ervas e em casa as cozinhava, durante vários ritos religiosos. Ela fazia pequenos sacos de pele de cabra e, quando estes eram preenchidos com misturas de ervas, ela os levava para o porto vizinho, para serem vendidos e assim aplacar os capitães dos navios. Dessa forma, ela fornecia seus próprios meios de sustento.

Por curiosidade, durante uma ocasião, abri um dos sacos. Minha mãe, sem saber o que tinha acontecido, vendeu-o. Eu havia retirado as ervas do [saco de] tecido de linho, o qual era ornamentado com bordados e apresentava vários símbolos. Entretanto, ao abrir este saco, eu a tinha defraudado de seu lucro. Minha mãe, inflamada de raiva, disse que me daria ao comandante [como serviçal] em lugar do saco, a fim de que ela pudesse ficar com o dinheiro. No dia seguinte, inesperadamente, o capitão levantou as velas [do barco] e zarpou do porto, sob um vento favorável, rumo à ilha da Noruega. Depois de vários dias sob o vento ascendente do norte, o navio foi levado [para as águas] entre a Noruega e a Inglaterra. Atravessou esse canal e dirigiu-se então para a Dinamarca, porque [o capitão] tinha [em seu poder] cartas de um bispo islandês, as quais deveriam ser entregues a Tycho Brahe, o dinamarquês, que vivia na ilha de Hveen. Eu era então um menino de catorze anos e estava ficando gravemente doente, devido ao balanço do navio e à temperatura incomum do ar. Quando [a carga do] navio havia sido desembarcada, assim como as cartas, o capitão me deixou na casa de um pescador da ilha e voltou a navegar, com a promessa de retornar [para me buscar].

Depois que as cartas lhe foram entregues, Brahe começou a me fazer muitas perguntas, em um tom muito alegre. Eu não o entendia, porque eu não conhecia a língua [dinamarquesa], exceto por algumas palavras. Ele dedicava todo o seu tempo para os seus alunos, os quais ele cuidava em grande número. Através do intermédio de Brahe, eles podiam frequentemente falar comigo. Depois de algumas semanas de prática, comecei a falar dinamarquês de uma forma tolerável. Eu não estava menos preparado para respondê-los do que eles estavam para me questionar. Fiquei maravilhado com muitos objetos [e assuntos] desconhecidos. Eu então relatei diversos acontecimentos recentes na minha pátria aos meus admiradores.

Finalmente, quando o capitão do navio voltou para me levar de volta, Brahe me manteve [ao seu lado]. Isso me deixou extremamente feliz.

Os exercícios astronômicos me agradavam em grau extraordinário. Durante noites inteiras, Brahe e seus alunos se dedicavam ao estudo da Lua e das estrelas, usando máquinas maravilhosas. Essa prática trouxe minha mãe de volta à mente, pois ela também conversava com a Lua de maneira frequente. Devido a esse fluxo de acontecimentos, embora eu fosse considerado quase um semibárbaro, devido ao lugar em que nasci e das minhas indigentes circunstâncias, cheguei ao conhecimento sobre a mais 
divina das ciências, [a astronomia], preparando o meu caminho para realizações maiores.

Depois de viver na ilha de Hveen por vários anos, eu ansiava por revisitar minha terra natal. Devido [ao conhecimento sobre] a ciência que eu havia adquirido, supus que não me seria difícil alcançar até mesmo algum grau honorífico em minha própria nação de homens inexperientes. Pedi uma permissão para me afastar do meu patrão [Tycho Brahe], despedi-me dele e fui a Copenhague. Meus companheiros de viagem livremente me levaram sob sua proteção, devido à minha familiaridade com sua língua e seu país. Retornei para casa cinco anos depois de eu ter partido.

Minha primeira fonte de alegria ao retornar foi descobrir que minha mãe ainda estava viva e continuava a prestar os mesmos serviços que ela anteriormente fazia. $\mathrm{Na}$ medida em que eu ainda estava vivo e provido de um meio de subsistência, [meu retorno] pôs um fim à sua contínua tristeza por ter abandonado seu filho em um ataque de raiva. O outono estava se aproximando, e aquelas longas noites nossas [da Islândia] estavam se aproximando. Em dezembro, o Sol mal se levantava um pouco ao meio-dia, estando novamente escondido da vista. Minha mãe permanecia perto de mim, agora que ela estava livre de seu trabalho, e não me deixava [só], não importando onde eu fosse. Por causa de minhas cartas de recomendação, fui interrogado sobre as terras que eu havia visitado, e [ouvi] até mesmo perguntas sobre os céus. Minha mãe tinha prazer em comparar a extensão do conhecimento que eu havia adquirido e o [conhecimento] que ela mesma descobriu como verdadeiro. Ela declarava que agora estava pronta para morrer, para que pudesse tornar seu filho o herdeiro daquela informação que apenas ela possuía.

Por natureza, eu tinha uma verdadeira sede de aprender coisas novas. Assim, eu perguntei a minha mãe sobre sua arte, e sobre quais professores em nosso país se destacavam acima do resto. Então, num certo dia, quando havia tempo livre para ela falar, ela repetiu da seguinte forma tudo o que sabia, desde o início: Duracotus, meu filho, o conhecimento está disponível não só nas outras províncias para as quais você viajou, mas também em nossa própria pátria. Você me fez perceber o encantamento de outras regiões. Entretanto, ainda que tenhamos frieza, escuridão e outros desconfortos que agora me oprimem, ainda assim abundamos em pessoas com talento. Temos entre nós espíritos muito dotados, os quais evitaram a maior luz de outras regiões, assim como o tagarelar dos homens, e, [ao contrário], buscaram nossas áreas sombreadas para conversar familiarmente conosco. Destes espíritos, nove foram importantes. Um deles, de longe o mais gentil e mais inocente, foi particularmente conhecido por mim. Este espírito me foi revelado por vinte e um sinais. Muitas vezes, em uma fração de segundo, eu fui transportada pelo seu poder para outras paragens que eu escolhi para mim. Mesmo que eu estivesse afastada de certos lugares por causa de sua distância, [ainda assim] eu ganhava entendimento perguntando sobre tais lugares, como se estivéssemos presentes lá. Ele, [o $D a-$ emon], relatou para mim muitos fatos sobre os objetos que você examinou com seus olhos, aceitos a partir de relatos ou extraídos de livros. Eu gostaria, especialmente, que você se tornasse um espectador, e [também] meu companheiro, daquela região sobre a qual ele me contou. Quão maravilhosas eram aquelas coisas que ele me disse sobre essa [região]! Ele havia conjurado Levânia.

Sem demora, concordei que ela deveria convocar seu professor. Sentei-me então no conselho, preparado para ouvir não só o propósito da viagem mas também a descrição da região. A região se encontrava na [estação da] primavera. A partir do momento em que a Lua estava [na fase] crescente, ela começava a brilhar, pois enquanto a Lua estava [na fase] crescente, o Sol há havia se escondido sob o horizonte, unindo-se ao planeta Saturno no signo de Touro. Minha mãe, afastando-se de mim na encruzilhada mais próxima e soltando poucas palavras, apresentou seu pedido em um intenso clamor. Depois que ela completou o cerimonial, ela retornou e, exigindo silêncio com a palma da mão direita estendida, sentou-se junto a mim. Mal tínhamos enrolado nossas cabeças com um pano (como era o costume), quando eis que surgiu o estertor de uma voz rouca e cantarolada, a qual imediatamente começou a relatar a história a seguir, mas na língua islandesa.

\subsection{Daemon 12 de Levânia}

A ilha de Levânia está localizada a cinquenta mil milhas alemãs para o alto da atmosfera. O caminho para esta ilha a partir da nossa Terra, e vice-versa, é muito raramente transposto; entretanto, quando é acessível, [a jornada] é fácil para o nosso povo. Todavia, o transporte de homens, unido como é ao maior perigo de vida, é mais difícil. Não admitimos homens sedentários, corpulentos ou fastidiosos neste séquito. Preferimos aqueles que passam o seu tempo cavalgando velozes cavalos de forma persistente, ou [aqueles] que navegam para as Índias com frequência, acostumados a subsistir com pães velhos requentados, alho, peixe seco e outros pratos desagradáveis. Há mulheres mais velhas, exauridas, que são especialmente adequadas para o nosso propósito. A razão para isso é bem conhecida. Desde a infância, tais pessoas estão acostumadas a pastorear cabras, ou usar mantos, enquanto trafegam através de passagens estreitas e pela imensa extensão da Terra. Embora os alemães não sejam adequados, não rejeitamos os corpos ressequidos dos espanhóis.

Toda a viagem, por mais distante que possa ser, é completada em um máximo de quatro horas. Nosso horário de partida acontece quando estamos mais ocupados, antes que a Lua comece seu eclipse em sua seção oriental. Se a Lua se tornar cheia enquanto ainda estivermos em nosso caminho, nossa viagem de retorno é impossível. A

12 Apesar da similaridade fonética com a palavra demônio, a palavra latina Daemon está mais associada a uma divindade, espírito ou entidade. 
ocasião se torna tão breve que temos poucos humanos [entre nós] e [praticamente] nenhum dos outros seres, exceto aqueles mais úteis para nós. Formando uma coluna, pegamos qualquer homem deste tipo e todos nós o empurramos para cima, levantando-o para as alturas. O choque inicial é a pior parte desse evento para ele, pois [o homem] é girado para cima como se [fosse lançado por] uma explosão de pólvora, voando então acima de montanhas e mares. Por isso, ele deve ser drogado com narcóticos e opiáceos antes de seu voo. Seus membros devem ser cuidadosamente protegidos, a fim de que eles não sejam separados dele (o corpo [separado] das pernas, a cabeça [separada] do corpo) e para que o recuo não venha a se espalhar em cada membro de seu corpo. Então, ele enfrenta novas dificuldades, como um frio intenso, e [tem a] respiração prejudicada. Estas circunstâncias, as quais são naturais aos espíritos, são aplicadas de maneira forçada ao homem. Nós continuamos em nosso caminho colocando esponjas umedecidas cobrindo nossas narinas. Quando a primeira seção da viagem se completa, nosso deslocamento se torna mais fácil. Assim, expomos nossos corpos livremente ao ar e afastamos nossas mãos. Todos esses seres são reunidos em uma bola dentro de si, devido à pressão, uma condição que nós mesmos produzimos por um mero sinal da cabeça. Finalmente, na chegada à Lua, cada corpo é dirigido para o seu lugar pretendido, por sua própria vontade. Este ponto crítico é de pouco utilidade para nós, espíritos, porque é excessivamente lento. Portanto, como eu disse, nós aceleramos por magnetismo ${ }^{13}$ e passamos à frente do corpo do homem, para [evitar] que por um impacto muito forte na Lua ele possa vir a sofrer qualquer dano. Quando o homem acorda, ele geralmente se queixa de que todos os seus membros sofrem de uma lassidão inefável, da qual, no entanto, ele se recupera completamente quando o efeito das drogas desaparece, quando então ele pode [voltar a] andar.

Ocorrem diversas outras dificuldades, as quais tomariam muito tempo para serem contadas [aqui]. Nada nos acontece que seja inteiramente ruim. Por quanto tempo essas sombras da Terra são as que habitamos na Lua de maneira compacta! Quando esses homens tiverem chegado a Levânia, já estaremos prontos. Eles, [os homens], parecem estar escalando de um navio para a terra. Lá, rapidamente nos retiramos para as cavernas e para os lugares sombrios enquanto o Sol estiver aberto, mas quando ele é eclipsado um pouco mais tarde, somos expulsos do nosso agradável lugar de repouso e forçados a acompanhar a sombra que parte. Nossa inventidade se exercita nesses momentos de decisão. Nós nos juntamos aos [outros] daemons desta província e uma sociedade se inicia quando o Sol começa a falhar sobre a localidade. Reunidos em multidões, nós nos desviamos do nosso curso em direção da sombra. E, se a sombra atinge a Terra com seu ponto afiado, o que muitas vezes acontece, nós caímos pesadamente sobre a Terra com nossos companheiros soldados, pois não nos é permitido outro resultado quando

\footnotetext{
13 Entendemos que, nessa passagem, a aceleração a qual Kepler se
} refere seria similar à ação da gravidade, no sentido atual do termo. os homens testemunham o eclipse do Sol. A partir disso, explica-se porque os eclipses do Sol são tão temidos [entre os habitantes de Levânia].

Como consequência, estes comentários serão feitos sobre a viagem ao longo da [própria] Levânia. Falarei sobre a própria forma da província, começando como fazem os geógrafos, a partir dos eventos que lhe acontecem de cima.

Mesmo que toda Levânia tenha a aparência de que há estrelas fixas em comum conosco, observamos, contudo, muitos movimentos e um número de planetas diferentes daqueles que vemos da Terra, fazendo com que toda a astronomia deles tenha outro significado.

Assim como os geógrafos dividem o globo terrestre em cinco zonas devido aos fenômenos celestes, Levânia também é constituída por dois hemisférios, o Subvolvanianos e o outro dos Privolvanianos. Destes dois hemisférios, os Subvolvanianos sempre veem Volva, ou nossa Terra, a qual, para eles, é como nossa Lua, enquanto os Privolvanianos estão completamente privados da visão de Volva. O círculo que divide seus hemisférios, semelhante ao coluro ${ }^{14}$ dos nossos solstícios, passa pelos polos do mundo e é chamado de Divisor.

Explicarei primeiro o que ambos os hemisférios possuem em comum. Toda a Levânia sofre as mesmas alternâncias de dia e de noite como nós, mas ao longo do ano, eles não têm outras mudanças anuais. Ao longo de toda a Levânia, seus dias são quase iguais às suas noites, exceto pelo fato de que para os Privolvanianos cada dia é regularmente menor do que a sua própria noite, enquanto que o dia dos Subvolvanianos é regularmente mais longo. Aquilo que é alterado, ao longo de um ciclo de oito anos, terá que ser mencionado mais tarde. Sob os dois polos, metade do Sol está escondida para a equalização da noite, enquanto a outra metade brilha, formando um círculo em torno das montanhas. Como as estrelas estão se movendo, Levânia parece estar não menos imóvel a seus habitantes do que nossa Terra a nós. Um de nossos meses é igual a uma de suas noites e um dia. Quando o Sol vai nascer no início de uma manhã, um sinal quase completamente novo do zodíaco é mais aparente no dia seguinte do que no dia anterior. Assim como em um de nossos anos, o Sol gira 365 vezes e as órbitas das estrelas fixas 336 vezes; ou, mais precisamente, em quatro anos o Sol gira 1461 vezes, mas as órbitas das estrelas fixas giram 1465 vezes para nós; então, para eles, em um ano o Sol gira em torno de doze vezes, enquanto a órbita de estrelas fixas gira [em torno de] treze vezes; ou, mais precisamente, em oito anos o Sol gira em torno de 99 vezes e as órbitas das estrelas fixas 107 vezes. Mas eles estão mais familiarizados com um ciclo de dezenove anos: nesse número de anos, o Sol se eleva 235 vezes e as estrelas fixas 254 vezes.

O Sol nasce no centro ou nas regiões mais interiores do [hemisfério] Subvolva quando o último quarto [da Lua] é visível para nós; logo, para as regiões mais interiores do [hemisfério] Privolva quando o primeiro quarto [da

\footnotetext{
$1 \overline{14}$ Em astronomia, um coluro é um círculo máximo da esfera celeste que passa pelo equinócio ou pelo solstício.
} 
Lua] aparece para nós. O que eu digo sobre as partes centrais deve ser entendido como todos os semicírculos conduzidos através dos polos e os médios em ângulos retos com o Divisor. Você pode chamá-los de semicírculos de Medivolva.

O círculo intermediário entre os polos, o qual determina o mesmo efeito que o Equador de nossa Terra, será chamado por esse mesmo nome, [Equador]. Ele corta o Divisor em partes iguais e o Medivolva em pontos opostos. O Sol passa sobre alguns lugares no Equador [de Levânia] em dois dias opostos do ano, precisamente no momento do meio-dia. Ao meio-dia, o Sol se desloca a partir do zênite para os outros pontos, os quais se localizam em ambos os lados dos polos.

Em Levânia, há alguma variação entre o verão e o inverno, mas que não deve ser comparada com as nossas próprias [estações], pois não as observamos nem nos mesmos lugares nem na mesma época do ano. Em um período de dez anos, seu verão muda de uma parte do ano estelar para a parte oposta, a partir de um mesmo local. Em um ciclo de dezenove anos estelares ou em 235 dias, o verão e o inverno ocorrem vinte vezes, na direção dos polos, enquanto no equador [essas estações ocorrem] quarenta vezes. Assim como temos os nossos meses, eles têm seis dias ao todo durante o verão, pois o resto [dos dias] pertence ao inverno. A mesma alternância é esparsamente sentida em torno do Equador, porque o Sol não divaga para os lados além de 50 [graus] para trás e para frente desses lugares. [Essa alternância] é mais sentida [em regiões] próximas dos polos, em lugares onde o Sol aparece ou desaparece, alternadamente, em intervalos de seis meses, assim como há na Terra aqueles de nós que residem sob um dos dois polos. O globo de Levânia também está dividido em cinco zonas, correspondendo um pouco às nossas zonas terrestres; isto é, as áreas tórrida e frígida têm escassamente 10 graus [de latitude] cada; todo o resto cai em proporção à nossa zona temperada. A zona tórrida passa através das partes médias do hemisfério metade do seu comprimento através de Subvolva e a outra metade através de Privolva.

Existem quatro pontos cardeais para as seções dos círculos do Equador [de Levânia] e do zodíaco. Chamamos estes pontos de equinócios e solstícios, e a partir dessas seções, dá-se o início do círculo zodiacal. Desde seu início até sua finalização, o movimento das estrelas fixas é muito rápido - de forma mais específica, [elas gastam] vinte anos tropicais, ou seja, definidos por um verão e um inverno. As estrelas fixas se deslocam através de todo o zodíaco em aproximadamente 26.000 anos, o que é bastante para o seu primeiro movimento.

A causa de seus movimentos secundários difere não menos daqueles que aparecem para nós [na Terra], embora sejam muito mais intrincados. Além das muitas desigualdades existentes entre nós e todos os seis planetas - Saturno, Júpiter, Marte, o Sol, Vênus e Mercúrio eles observam a ocorrência de outros três [movimentos secundários]; nomeadamente, dois de longitude, sendo o primeiro diurno e o segundo observado ao longo de um ciclo de oito anos e meio; o terceiro [movimento secundário] é de latitude e [ocorre] ao longo de um período de dezenove anos. Os Privolvanianos do centro observam o Sol ao meio-dia mais do que as suas contrapartes de outras regiões, enquanto os Subvolvanianos observam menos do que se o Sol nascesse. Ambos são da mesma opinião que o Sol se inclina para o hemisfério Subvolva por alguns minutos, para frente e para trás da eclíptica e, então, [se desloca] entre as estrelas fixas. Estas variações, como eu disse, são restauradas ao longo de um espaço de dezenove anos para suas marcas anteriores. Este itinerário toma conta um pouco mais de Privolva e um pouco menos de Subvolva. Embora o Sol e as estrelas fixas estejam pressagiados a cair igualmente em torno de Levânia durante seu primeiro movimento, o Sol, contudo, aumenta para os Privolvanianos ao meio-dia, mas quase nada sob as estrelas fixas. Ao meio-dia, o Sol aparece [por um tempo] muito rápido para os Subvolvanianos, embora o contrário seja verdadeiro sobre a meia-noite. Como resultado, sob as estrelas fixas, observa-se que Sol dá alguns "saltos", por assim dizer, separados para cada dia.

O mesmo é verdade para Vênus, Mercúrio e Marte, mas no caso de Júpiter e Saturno [esses movimentos secundários] são quase imperceptíveis.

Entretanto, o movimento de cada dia não é o mesmo à mesma hora de cada dia. Assim, às vezes, [esse movimento] é mais lento para o Sol do que para todas as estrelas fixas, e é ainda mais rápido na parte oposta do ano na mesma hora. Esta lentidão [do movimento] vai para frente e para trás durante os dias do ano, de tal forma que, se agora ela se ocupar do verão, então será o inverno que sentirá tal [pequena] rapidez em outro ano. Tudo isso ocorre em um ciclo absoluto, ao longo de um tempo pouco menor que nove anos. $\mathrm{O}$ dia se torna mais longo do que a noite devido a uma lentidão natural, e não da forma como o temos na Terra, [na qual tal diferença ocorre] por uma seção desigual da órbita de um dia natural.

Embora a lentidão caia sobre o [hemisfério] Privolva à meia-noite, ela realiza seu desvio antes do dia seguinte; se, por outro lado, ela é concluída durante o dia, então a noite e o dia são iguais, algo que acontece uma vez em nove anos. Isso é completamente diferente para o [hemisfério] Subvolva.

Tais características são comuns a ambos os hemisférios.

\subsection{Sobre o hemisfério Privolva}

O que caracteriza separadamente cada hemisfério é a grande diferença entre eles. Não só a presença e a ausência de Volva leva a espetáculos bastante diferentes, mas esses fenômenos usuais diferem tanto aqui e ali em seus efeitos que se poderia, talvez mais corretamente, dizer que o hemisfério Privolva intempera o temperado Subvolva. A noite dos Privolvanianos dura quinze ou dezesseis de nossos dias, terrível e com sombras intermináveis, assim como são nossas noites sem Lua. Os raios de Volva nunca 
brilham sobre eles. Por esta razão, tudo se torna rígido devido ao gelo, à geada e aos ventos mais intensos e poderosos. Um dia então se segue, com duração [equivalente] a catorze de nossos dias, ou um pouco menos do que aquele em que o Sol aparece com maior [tamanho]. O Sol é lento sob as estrelas fixas e não há ventos. Então, [o hemisfério] se torna intoleravelmente quente. Dessa forma, para o espaço de um dos nossos meses ou de um dia levaniano e em um mesmo lugar, o calor se torna quinze vezes mais quente do que a nossa África, e o frio, insuportável.

Em especial, deve-se notar que o planeta Marte é, às vezes, observado por aqueles [que estão] nas partes centrais do Privolva à meia-noite, e para outros [observadores] no início de sua própria noite, com quase o dobro do [tamanho aparente que é] visto por nós.

\subsection{Sobre o Hemisfério Subvolva}

À medida que atravesso este hemisfério, começo [a encontrar] com seus habitantes fronteiriços, os quais vivem no círculo Divisor. Um fato particular para eles é a observação das digressões de Vênus e Mercúrio em relação ao Sol, [as quais parecem ser] muito maiores do que como nós [as percebemos]. Para essas mesmas pessoas, Vênus aparece em certos momentos como tendo mais que o dobro [do tamanho] da nossa visão de Vênus, especialmente para aqueles que vivem no Polo Norte [de Levânia].

A mais agradável de todas as ocupações em Levânia é a contemplação de Volva. Os Levanianos apreciam a visão de Volva, da mesma forma que nós fazemos com nossa Lua, [visão esta] que os Privolvanianos carecem completamente, porque estão profundamente dentro [do astro]. Por causa da perene presença de Volva, esta região é chamada Subvolva, assim como o resto é chamado Privolva, porque [essa outra região] é privada da visão de Volva.

Quando a nossa Lua se torna cheia e passa acima de prédios distantes, nós, moradores da Terra, a observamos de forma similar a um círculo aberto em um grande barril de madeira. Quando ela se eleva para o meio do céu, a Lua traz à mente algo como a forma de um rosto humano. Os Subvolvanianos veem Volva no meio de seu próprio céu - Volva toma esta posição para aqueles que habitam no meio ou no umbigo (sic) deste hemisfério - com um diâmetro um pouco menos de quatro vezes maior do que a nossa Lua para nós, de modo que, se estabelecermos uma comparação de discos, a superfície de Volva [parece] ser quinze vezes maior do que a nossa Lua. Para aqueles em que Volva continuamente se desvia de forma rápida para o horizonte, [Volva] aparece na forma de uma montanha de fogo distante.

Assim como diferenciamos nossas regiões por meio de elevações maiores ou menores em relação ao polo, embora não tenhamos necessariamente de ver o polo com os nossos olhos, [da mesma forma] a altitude do sempre presente Volva preenche a mesma necessidade para eles, variando para os diferentes lugares.
Como eu disse, Volva paira diretamente sobre determinados lugares enquanto parece ter sido sugado para baixo, [aparecendo] perto do círculo do horizonte para as regiões restantes. Em todos os lugares, [Volva] transmite a evidência de uma altitude sempre constante.

Ainda assim, os Subvolvanianos têm seus próprios polos, os quais não estão entre essas estrelas fixas, onde temos os polos do [nosso] mundo, mas em torno de outras estrelas fixas, sendo então estes sinais eclípticos dos polos para nós. Em dezenove anos lunares, estes polos passam por pequenos círculos ao redor dos polos da eclíptica sob a constelação de Dragão e suas opostas, [a constelação de] Dourado ${ }^{15}$ [a constelação de] Peixe Austral ${ }^{16}$ e a Grande Nuvem de Magalhães ${ }^{17}$ Quando esses polos, em um quarto de círculo, estão longe de Volva, de modo que as regiões possam ser classificadas tanto de acordo com os polos quanto de acordo com Volva, se torna evidente quão grande é a vantagem com que nos superam [em termos de localização geográfica]. Estes polos marcam a longitude dos lugares a partir do imóvel Volva, e marcam a latitude tanto a partir de Volva quanto pelos seus [próprios] polos. Isso é diferente para nós, porque não temos meios de obter nossa longitude, com a exceção de subserviente e pouco distinguível inclinação de uma agulha magnética.

O Volva, para os Subvolvanianos, permanece como se tivesse sido fixado com um prego no céu, ficando imóvel neste lugar. Outras estrelas e o próprio Sol atravessam [o céu] do nascer ao pôr do sol. [Também] não existe uma noite em que nenhuma das estrelas fixas no zodíaco se esconda atrás de Volva e emerja novamente na região oposta. Embora as mesmas estrelas fixas não realizem isso todas as noites, ainda assim, todas elas mudam [de posição] completamente entre si; isto é, aquelas que se movem até seis ou sete graus a partir da eclíptica. Em dezenove anos, todo o circuito é realizado, fazendo com que elas retornem exatamente às suas posições originais.

Para os Subvolvanianos, Volva não aumenta nem [chega a] diminuir [para um tamanho] menor que a nossa Lua. A mesma razão existe tanto para a presença do Sol quanto para a digressão de Volva. Se estudarmos sua natureza, o tempo é o mesmo; mas [enquanto] os Subvolvanianos os medem por um método, nós o fazemos por outro. Os Subvolvanianos pensam que um dia e uma noite é o período de tempo durante o qual todos os aumentos e diminuições de Volva são concluídos. Nós chamamos esse período de tempo de um mês [terrestre]. Volva raramente se esconde para os Subvolvanianos, mesmo [na fase] nova de Volva, devido ao seu tamanho e brilho, especialmente para os habitantes polares de Subvolva, para os quais falta o Sol nessa época. Ao meio-dia, Volva vira suas extremidades para cima em relação aos Subvolvanianos, no próprio período intervolviano. Em geral, para aqueles que habitam entre Volva e os polos sob o círculo de Medivolva, [a fase] nova de Volva é o sinal do meio-dia e do primeiro quarto da noite. A [fase] cheia de Volva

\footnotetext{
15 No original, Xiphias.

16 No original, Passer.

17 No original, Nebecula Major.
} 
separa partes iguais da noite, e o último quarto [de Volva] traz o Sol de volta. Aqueles que têm Volva e os polos fixados no horizonte vivem na interseção do Equador com o Divisor. Sua manhã e noite vêm [nas fases] nova e cheia de Volva, e seu meio-dia ou meia-noite, nos quartos [crescente e minguante]. A partir dessas observações, podemos tirar conclusões sobre aqueles que vivem entre os lugares descritos acima.

Os Subvolvanianos diferenciam as horas do dia por meio destas e outras fases de Volva, de modo que quanto mais perto o Sol e Volva pareçam estar, tanto mais perto está o meio-dia para os Subvolvanianos, assim como a noite ou o pôr do sol para os Medivolvanianos. Os Subvolvanianos estão muito mais bem equipados do que nós para medir os períodos de noite, que regularmente dura catorze de nossas horas. Dissemos que fora daquela sequência de fases de Volva, onde a [fase] plena de Volva marca meia-noite para o próprio Medivolva, [o próprio] Volva já [permite] distinguir suas horas. Embora Volva não pareça de modo algum mudar de lugar, nossa Lua, ao contrário, gira em um mesmo lugar e explica adequadamente o número surpreendente de marcas que mudam persistentemente desde o seu nascimento até o seu poente. Quando as marcas se reiniciam após tal revolução, os Subvolvanianos contam uma hora do seu tempo, [a qual é] igual a pouco mais de um de nossos dias e noites. Esta é, então, a única medida uniforme do tempo. Nós indicamos anteriormente que o Sol e as estrelas diariamente circulam em torno dos habitantes da Lua de uma maneira desigual do fato de que esta perturbação de Volva especialmente é projetada, se você compará-la com os prolongamentos de estrelas fixas a partir da Lua.

A parte superior do norte de Volva parece ter duas metades; isto é, uma que é bastante encoberta, como se estivesse coberta com marcas contínuas, e outra um pouco mais clara, espalhando-se no norte uma faixa brilhante na linha divisória de ambos. A figura é difícil de explicar.

Em sua seção mais oriental, percebemos algo como a frente de uma cabeça humana, cortada nos ombros, inclinando-se para beijar uma menina vestida com uma longa túnica, enquanto seu braço se estende para trás e atrai um sedutor. A parte mais larga e maior da mancha projeta-se para o oeste sem qualquer forma visível. Na outra metade de Volva, um brilho é espalhado mais amplamente do que a mancha. Você pode visualizá-lo como a imagem de um sino pendurado para baixo em uma corda, balançando para o oeste. As partes superior e inferior não podem ser comparadas com nada.

Não basta que Volva [permita] distinguir as horas subvolvanianas do dia desta forma, mas sim que dê indicações claras das partes do ano se alguém prestar atenção a ele ou se o propósito das estrelas fixas escapar a alguém. Quando o Sol passa para Câncer, Volva indica claramente o Polo Norte de sua perturbação. Há uma pequena mancha escura acima da imagem da menina, inserida no meio do brilho. Este brilho é deslocado da parte mais alta e mais afastada de Volva para o leste; e, a partir daqui, uma vez que fez a descida no disco, move-se para o oeste.
A marca novamente se retira da última posição para o topo e para o leste de Volva, e sempre aparece lá. Entretanto, quando o Sol entra em Capricórnio, essa mancha não pode ser vista em qualquer lugar, porque todo o círculo, junto com seu polo, se esconde atrás do corpo de Volva. Durante estas duas partes do ano, as manchas caem diretamente para o oeste. Durante os períodos intermediários localizados a leste ou em Libra, as manchas ou se afundam transversalmente ou sobem em uma linha curva. Esta apresentação nos ensina que, quando o centro do corpo de Volva permanece em repouso, os polos da perturbação no círculo ártico circundam esses polos uma vez em um ano.

Os observadores mais diligentes veem que Volva não permanece com o mesmo tamanho. Durante as horas do dia em que as estrelas se movem rapidamente, o diâmetro de Volva é muito maior, de modo que é claramente quatro vezes maior que a nossa Lua.

Agora, o que direi sobre os eclipses do Sol e de Volva que ocorrem em Levânia, ao mesmo tempo em que os eclipses do Sol e da Lua ocorrem aqui no globo terrestre, mas, evidentemente, por razões diferentes? Quando vemos o eclipse total do Sol, Volva eclipsa para eles, enquanto que quando a nossa Lua eclipsa, o Sol é eclipsado para eles. No entanto, eu não concordo exatamente com todas essas coisas. Eles muitas vezes veem eclipses parciais do Sol mesmo quando nenhuma parte da Lua não se mostra para nós. Pelo contrário, eles são frequentemente isentos de eclipses de Volva quando observamos nossos eclipses parciais do Sol. Eles têm eclipses de Volva durante a fase plena de Volva, assim como nós temos o nosso [eclipse] da Lua durante a Lua cheia; eles têm eclipses do Sol na [fase] nova de Volva, da mesma forma que temos [eclipses solares] na Lua Nova. Já que eles têm dias e noites mais longos, eles experimentam eclipses mais frequentes de ambos os corpos celestes. Um grande número de nossos eclipses trafega em direção dos nossos antípodas, e [no caso] deles, para seus antípodas. Os Privolvanianos não veem nenhum destes [eclipses], enquanto apenas os Subvolvanianos observam tudo.

Os Subvolvanianos nunca veem um eclipse total de Volva, mas através do corpo de Volva lá atravessa certa mancha pequena, avermelhada em suas bordas e escura no centro. Esta pequena mancha faz a sua entrada da seção oriental de Volva e emerge através da borda ocidental; o mesmo é verdadeiro para os pontos naturais de Volva, antecipando-os rapidamente. A duração se estende até uma sexta parte das suas horas, ou quatro das nossas.

A causa de um eclipse solar [visível para os] Subvolvanianos é Volva, assim como a nossa Lua causa o nosso [eclipse solar]. Isso não pode acontecer, na medida em que Volva parece quatro vezes maior que o Sol, sem que o Sol passe do leste pelo sul atrás do inamovível Volva para o oeste. O Sol, então, desapareceria muito perto de Volva, com o resultado de que parte ou todo o corpo do Sol estaria escondido por ele. Com frequência, há um eclipse muito perceptível do corpo inteiro do Sol, porque dura por várias de nossas horas, quando a luz do Sol 
e de Volva é eclipsada ao mesmo tempo. Esta é uma experiência importante para os Subvolvanianos, os quais têm outras noites não tão escuras quanto seus dias, por causa do brilho e magnitude do sempre presente Volva. Durante um eclipse do Sol, ambos os corpos celestes, o Sol e Volva, estão escondidos dos Subvolvanianos.

No que consta aos Subvolvanianos, os eclipses do Sol têm um ponto em comum. Acontece com frequência que o brilho se eleva do lado oposto quando o Sol mal se encontra encoberto, atrás do corpo de Volva, como se o Sol se tivesse expandido e abraçado todo o corpo de Volva; contudo, em algum outro tempo e em muitas seções, o Sol aparece menos do que Volva. A escuridão completa nem sempre ocorre, a menos que os centros dos corpos coincidam estreitamente e o arranjo regular dos centros diáfanos se una. [Nesse caso,] Volva desaparece de forma repentina, de modo que não pode ser discernida, embora o Sol se esconda completamente atrás de Volva, exceto nas ocasiões dos eclipses mais longos. No início de um eclipse total, no entanto, Volva ainda permanece branco em algumas seções do Divisor, como se houvesse um carvão em brasa presente após a extinção da chama. Após esta brancura desaparecer, o ponto médio do eclipse mais longo é alcançado; pois isso não se extingue em nada menos que o eclipse mais longo. Quando a brancura de Volva retorna (em lugares opostos do círculo Divisor), a visão do Sol também se aproxima. De alguma forma, ambos os corpos desaparecem na fase intermediária dos eclipses mais longos.

Estas são as aparições em ambos os hemisférios de Levânia: em Subvolva, bem como em Privolva. A partir dessas considerações, passar um julgamento silencioso sobre o quanto os Subvolvanianos diferem dos Privolvanianos em outros aspectos não é difícil para mim.

Uma noite subvolvaniana, mesmo equivalendo a catorze de nossas noites longas, ilumina o solo e o protege do frio, devido à presença de Volva. Uma massa tão grande e tão brilhante não pode deixar de mantê-lo quente.

Embora o dia de Subvolva tenha a irritante presença do Sol durante nossas quinze ou dezesseis noites, ainda assim, o Sol não tem forças menos hostis. Os luminares unidos atraem toda a água para esse hemisfério até que a superfície esteja completamente coberta, de modo que muito pouco dela seja visível. Pelo contrário, quando toda a água foi removida do hemisfério Privolva, este se torna seco e frio. [Isso ocorre] porque os hemisférios têm os luminares divididos entre si: a noite vem sobre o [hemisfério] Subvolva e o dia sobre o [hemisfério] Privolva. As águas são divididas de modo que os campos subvolvanianos são despojados de tudo, enquanto os privolvanianos desfrutam de uma abundância de umidade como um alívio insignificante para o calor.

A totalidade de Levânia não se estende por mais de mil e quatrocentas milhas alemãs em circunferência, uma quarta parte de nossa Terra. Possui montanhas muito altas, vales muito profundos e largos e, em consequência, perde muito em relação à nossa Terra em termos de perfeita esfericidade. Toda a superfície é porosa, como se tivesse sido perfurada, através de cavernas ocas e [também] cavernas contínuas, especialmente prolongadas através do [hemisfério] Privolva. Estes lugares ocos são os principais meios à disposição dos Privolvanianos para se proteger do calor e do frio.

Tudo o que brota da terra ou caminha sobre a superfície é de um tamanho monstruoso. Os aumentos de tamanho são muito rápidos. A vida é de curta duração, porque todos os seres vivos crescem a uma enorme massa corporal. Os Privolvanianos não têm moradia fixa. No espaço de um único dia, atravessam todo o seu mundo em hordas, seguindo as águas que recuam, seja por meio de pernas mais longas do que as dos nossos camelos, usando asas ou [viajando] em barcos. Se um atraso de muitos dias é necessário, eles rastejam pelas cavernas, de acordo com a natureza de cada um. Há muitos mergulhadores entre eles e todos os seus seres vivos respiram muito lentamente. Ao combinar a natureza com a arte, eles podem se refugiar no fundo das águas profundas. Dizem que aqueles que estão nas profundezas da água sofrem com o frio, enquanto as ondas superiores estão fervendo devido ao calor do Sol. Aqueles que permanecem na superfície são fervidos pelo Sol do meio-dia e servem como alimento para os colonos errantes. Em geral, o hemisfério Subvolva é comparável favoravelmente com os nossos cantões, cidades e jardins, enquanto o [hemisfério] Privolva se assemelha a nossos campos, florestas e desertos. Outras criaturas, as quais acham a respiração mais necessária, se recolhem em cavernas que são abastecidas com água por canais estreitos, a fim de que a água possa esfriar gradualmente em seu longo caminho; entretanto, quando a noite vem, eles saem para comer. A casca das árvores, a pele das criaturas vivas - ou qualquer outra coisa que tome seu lugar - ocupa a maior parte da massa corporal, porque é esponjosa e porosa. Se qualquer criatura é tomada de surpresa no calor do dia, sua pele fica dura e queimada, vindo [então] a cair durante a noite. Plantas no solo, e mesmo algumas na parte superior das montanhas, brotam e morrem no mesmo dia, criando espaço diariamente para as novas coisas em crescimento.

Sua natureza é, em geral, como uma serpente. Elas têm um estranho amor para se aquecer no sol do meio-dia, mas apenas perto de suas cavernas, para que elas [(as criaturas)] possam se recolher de forma rápida e segura.

Outras [criaturas], cujos espíritos foram exauridos pelo calor do dia, perdem a vida, mas ressuscitam à noite, devido a alguma causa paradoxal, tal como a produção de moscas aqui na Terra. Aqui e ali, todo o chão [é coberto] por massas dispersas, na forma de cones de pinheiro. Suas cascas são queimadas pelo sol durante o dia e morrem, mas à noite, produzem criaturas vivas quando os esconderijos são abertos.

No hemisfério Subvolva, uma forma especial para alívio do calor são as nuvens ininterruptas e as tempestades, as quais por vezes ocorrem ao longo da metade ou mais da metade dessa região.

Quando eu cheguei a esta parte de meu sonho, o vento aumentou e se fez acompanhar de uma estron- 
deante chuva, perturbando meu sono e encerrando um dos últimos livros que eu havia trazido de Frankfurt. Quando o Daemon, o falante Duracotus, o filho com sua mãe Fiolxhilda e os ouvintes tinham sido [todos] deixados para trás, voltei a meus sentidos, e da mesma forma que eles tinham estado com a cabeça coberta, descobri que minha cabeça estava em uma almofada e meu corpo estava embrulhado em um cobertor.

\section{Considerações finais}

Toda tradução envolve riscos, e a "tradução de uma tradução", como a apresentada nesse artigo, é ainda mais perigosa, pois más interpretações ou escolhas por parte do tradutor original podem ser repassadas ou até mesmo amplificadas na nova tradução - e.g. as deficiências apresentadas nas traduções das obras de Lev Vygotsky para o português, conforme aponta Prestes [21]. Assim, buscamos minimizar as chances de interpretações equivocadas comparando continuamente nossa tradução com os apontamentos de Nicolson [4] e Christianson [14] acerca do contexto da obra. Apesar dessa ressalva, entendemos que uma tradução direta da obra em latim seria a ideal, e rogamos para que especialistas nessa língua clássica venham a apresentá-la em algum momento no futuro. Apesar desse receio, defendemos que o caráter de ineditismo da disponibilidade do texto em português justifica o nosso esforço de tradução.

Entendemos que a leitura da obra é relevante para os pesquisadores ou interessados na história da ciência pelo caráter duplo que a mesma apresenta, revelando-se ao mesmo tempo mística e racional. Tal dualidade, vale lembrar, transparece ao longo de diversos episódios da biografia de Kepler. A obra em questão permite, assim, uma complementaridade com outros textos do autor. Em particular, destacamos a passagem na qual Duracotus encontra Tycho Brahe, na qual Kepler (representado pela persona de Duracotus) exibe grande admiração pelo astrônomo, mas ao mesmo tempo, demonstra até mesmo alguns arroubos de superioridade em relação aos outros discípulos do dinamarquês.

Consideramos uma infelicidade que o manuscrito não tenha sido ilustrado pelo autor, ao contrário de outras obras de Kepler, e.g. seu seminal livro de óptica acerca da refração em telescópios, intitulado Dioptrice [22]. Há poucas ilustrações presentes também nas notas do autor; em especial, destaca-se um esquema para os eclipses solares e lunares (Figura 2), o qual é usado por Kepler, em algumas notas explicativas, para explicar as diferenças na observação de tais fenômenos na Terra e nos dois hemisférios lunares (Privolva e Subvolva, conforme a nomenclatura utilizada em Somnium).

A ausência dessas ilustrações, entretanto, pode se revelar uma oportunidade para trabalhos em sala de aula a partir do texto: assim, poder-se-ia trabalhar com a ilustração ou esquematização de certas passagens, sendo que os próprios estudantes deveriam elaborar tais construções a partir das descrições de Kepler. Dois exemplos

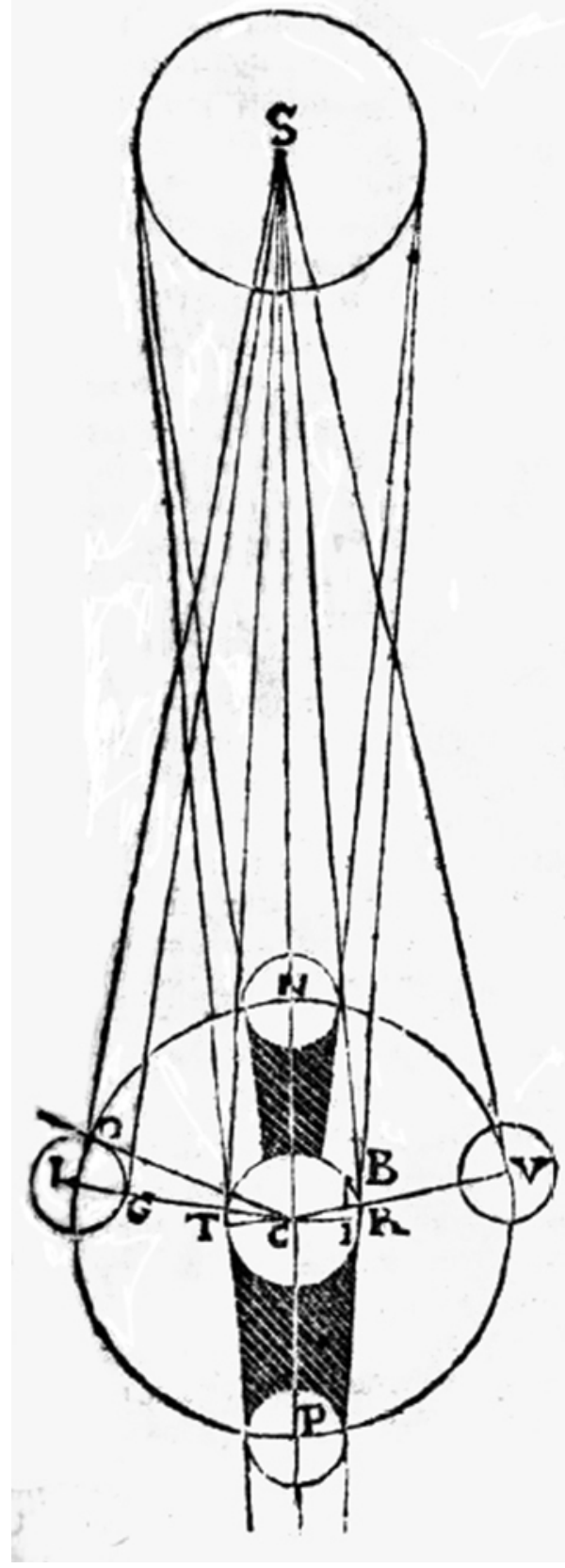

Figura 2: Esquema de Johannes Kepler para os eclipses solares e lunares, presente nas notas de Somnium. Nesse esquema, $S$ representa o centro do Sol e $C$ o centro da Terra. A Lua é mostrada em quatro fases: $N$ (nova), $V$ (minguante), $P$ (cheia) e $L$ (crescente). A figura foi extraída do original de Kepler [2] (p.39) e foi trabalhada em um editor de imagens para ampliação da sua qualidade.

principais, a nosso ver, se destacam: as fases de Volva (ou seja, a Terra) vistas a partir de cada hemisfério da lua, assim como a forma pela qual os eclipses seriam visualizados em cada um destes hemisfério.

Embora a leitura não nos pareça cansativa, dada a pequena extensão do texto, talvez ela possa se revelar por demais extensa para alunos na educação básica, devido a algumas passagens mais herméticas. Assim, caso o 
professor deseje trabalhar o texto, ele poderia optar por uma contextualização geral, relatando o início do sonho de Kepler, e lidar então com passagens específicas do manuscrito, as quais poderiam ser lidas pelos estudantes. Em especial, acreditamos que trechos de Somnium são adequados à abordagem de tópicos como as fases da Lua, a comparação entre os sistemas geocêntrico e heliocêntrico, a dependência de um movimento em relação a um referencial e, claro, o estudo dos eclipses.

No tocante a esses relevantes fenômenos celestiais, poder-se-ia requerer que os estudantes desenvolvessem seus próprios modelos (escritos, geométricos ou a partir de materiais concretos) para aquilo que seria visto por um observador na Lua durante um eclipse solar - quando o Sol é encoberto pela Terra - ou "terrestre" - quando a sombra da Lua encobre parcialmente a superfície da Terra. Posteriormente, os modelos construídos poderiam ser comparados com os escritos de Kepler. Outra possibilidade de trabalho pedagógico envolveria a comparação das fotos obtidas pelas missões norte-americanas Apollo [23], nos anos 1960 e 1970, as quais poderiam ser contrastadas com as descrições de Kepler, para verificar se as previsões do filósofo natural se revelaram corretas mais de três séculos antes dos primeiros observadores humanos virem a pisar na Lua.

\section{Referências}

[1] Carl Sagan, Cosmos: A Personal Voyage - Ultimate Edition. Via Vision Entertainment, 2017, 3 Blu-ray (780 minutos).

[2] J. Kepler, Somnivm, Seu Opvs Posthvmvm de Astronomia Lvnari (Sagani Silesorium, Frankfurt, 1634), $1^{\mathrm{a}}$ ed., p. 1-28. Disponível em https://archive.org/ details/den-kbd-pil-130011021345-001, acesso em 16/04/2017.

[3] D. Anderson, Renaissance Quarterly 22, 40 (1969).

[4] M. Nicolson, Journal of the History of Ideas 1, 259 (1940).

[5] C. de Bergerac, A Voyage to the Moon (Doubleday and McClure, New York, 1899), 271 p, disponível em https: //archive.org/details/avoyagetomoon01pagegoog. acesso em 18/05/2017.

[6] O. Gingerich, Science 157, 416, (1967).

[7] D. Swinford, Through the Daemon's Gate: Kepler's Somnium, Medieval Dream Narratives, and the Polysemy of Allegorical Motifs (Routledge, New York, 2006), 223 p.

[8] B. Johnson, Computer 49, 91 (2016).

[9] J. Verne, De la Terre à la Lune : Trajet Direct en 97 Heures 20 Minutes (J. Hetzel, Paris, 1872), $22^{\mathrm{a}}$ ed., $378 \mathrm{p}$, disponível em https://archive.org/details/ delaterrelalu00vern acesso em 29/05/2017.

[10] A. Clarke, 2001 Uma Odisseia no Espaço (Aleph, São Paulo, 2013), 1ª ed., 1 ${ }^{\mathrm{a}}$ reimp, $336 \mathrm{p}$.

[11] P. Anderson, Tau Zero (Doubleday, New York, 1970), $1^{\mathrm{a}}$ ed., $208 \mathrm{p}$.

[12] M. Gleiser, $O$ Sonho de Kepler, disponível em http://www1.folha.uol.com.br/fsp/ciencia/ fe0804200702.htm acesso: 12/05/2017.

[13] R. Bozzetto, Science Fiction Studies 17, 370 (1990).

[14] G. Christianson, Science Fiction Studies 3, 79 (1976).
[15] E. Rosen, Kepler's Somnium. The Dream, or Posthumous Work on Lunar Astronomy (Dover, New York, 2003), $1^{\text {a }}$ ed., $1^{\text {a }}$ reimp., $255 \mathrm{p}$.

[16] P. Kirkwood and J. Lear, Kepler's Dream: With the Full Text and Notes of Somnium, Sive Astronomia Lunaris Joannis Kepler (University of California Press, Berkeley, 1965), $1^{\mathrm{a}}$ ed.

[17] N. Falardeau, The Somnium Astronomicum of Johann Kepler translated, With Some Observations on Various Sources. Dissertação de Mestrado em Artes/Latim, Creighton University, 1962, p. 8-33, disponível em http://hdl.handle.net/10504/109241, acesso em $19 / 06 / 2017$.

[18] L. Dubeck, S. Moshier and J. Boss, Science in Cinema: Teaching Science Fact Through Science Fiction Films (Teachers College Press, New York, 1988), $1^{\mathrm{a}}$ ed., 187 p.

[19] M. Dark, The Physics Teacher 43, 463 (2005).

[20] L. Piassi e M. Pietrocola, Educação e Pesquisa 35, 525 (2009).

[21] Z. Prestes, Quando Não É A Mesma Coisa: Análise de Traduções de Lev Semionovitch Vigotski no Brasil: Repercussões no Campo Educacional. Tese de Doutorado em Educação, Universidade de Brasília, 2011.

[22] J. Kepler, Dioptrice seu demonstratio eorum quae visui Gamp; visibilibus propter Conspicilla ita pridem inventa accidunt (Augustae Vindelicorum, Augsburg, 1611), 128 p, disponível em https://archive.org/details/ DioptriceByJohannesKeplerAkaIoannisKepleri, acesso em 19/05/2017.

[23] Apollo Image Gallery, NASA, 2017. Disponível em https: //www.nasa.gov/mission_pages/apollo/images.html, acesso em 19/05/2017. 